
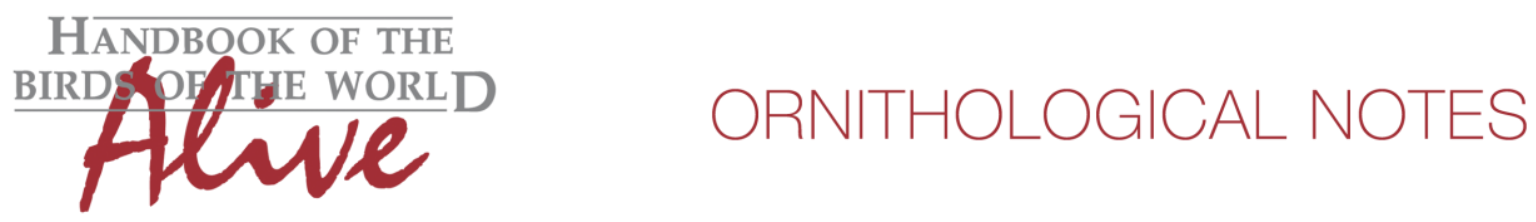

\title{
Notes on the vocalizations of Plain Wren (Thryothorus modestus) and Canebrake Wren (Thryothorus zeledoni)
}

\section{Peter Boesman}

In the following we briefly analyze and compare voice of the two races of Plain Wren (Thryothorus modestus), and Canebrake Wren (Thryothorus zeledoni). We also try to quantify the extent of any vocal differences using the criteria proposed by Tobias et al. (2010), as a support for taxonomic review. We have made use of sound recordings available on-line from Xeno Canto (XC).

Just like some other members of this genus, T. modestus has a 'short song' consisting of a short phrase of one or a few notes repeated at intervals, and a synchronous duet song in which both members of a pair sing continuously over a longer period.

Studies (Mann et al. 2003 and 2009) have actually revealed that the short song is a so-called 'I phrase' of the male bird, and the duet song actually starts with the same short song ('I phrase' of male) followed by some notes by the female (A phrase of female) and other notes of the male (B phrase of male), delivering a resulting 'IABABAB...'.

Some examples of such IABABAB.. duets:

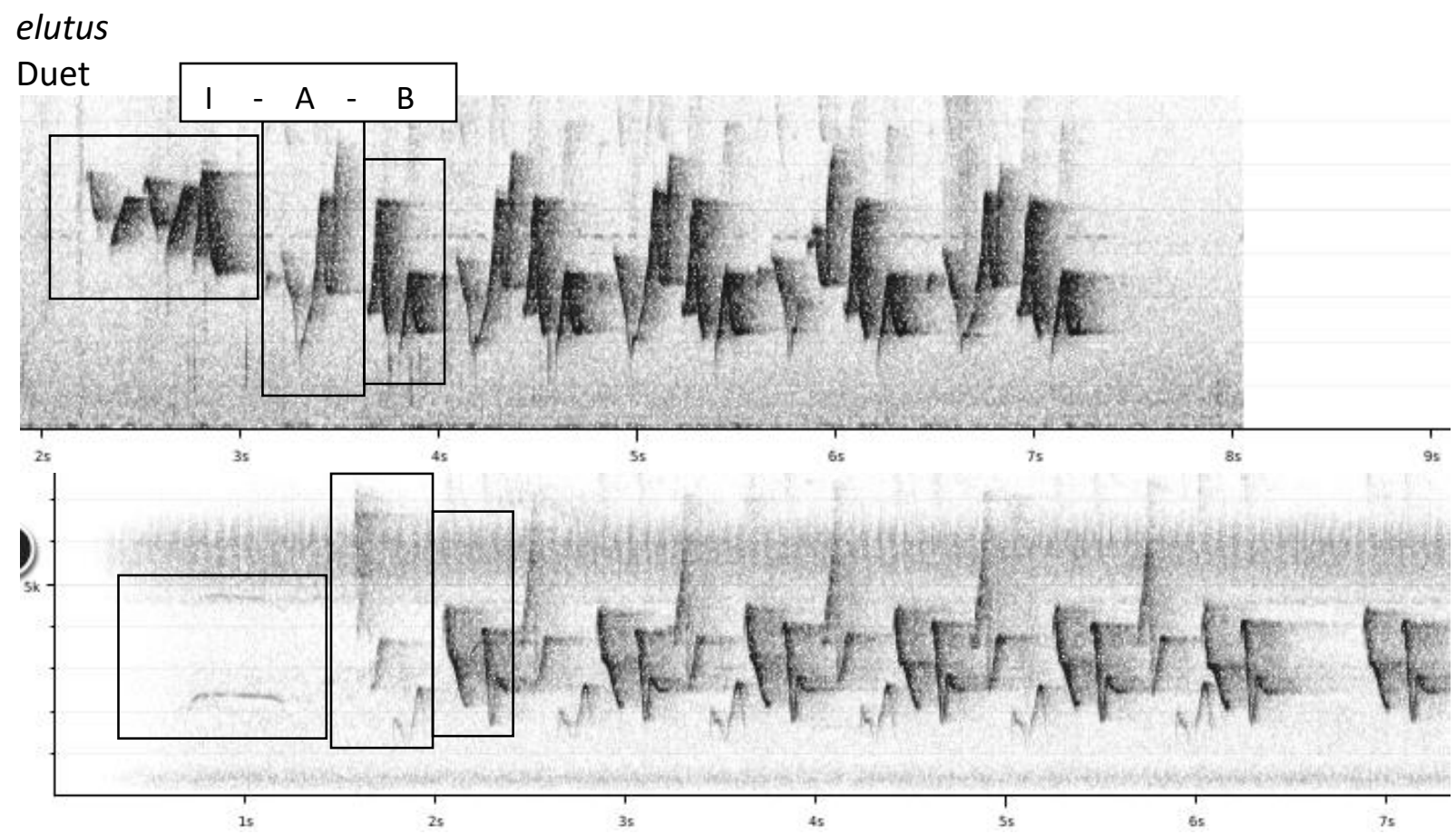


HANDBOOK OF THE

BIRDAPITHE WORLD ORNITHOLOGICAL NOTES

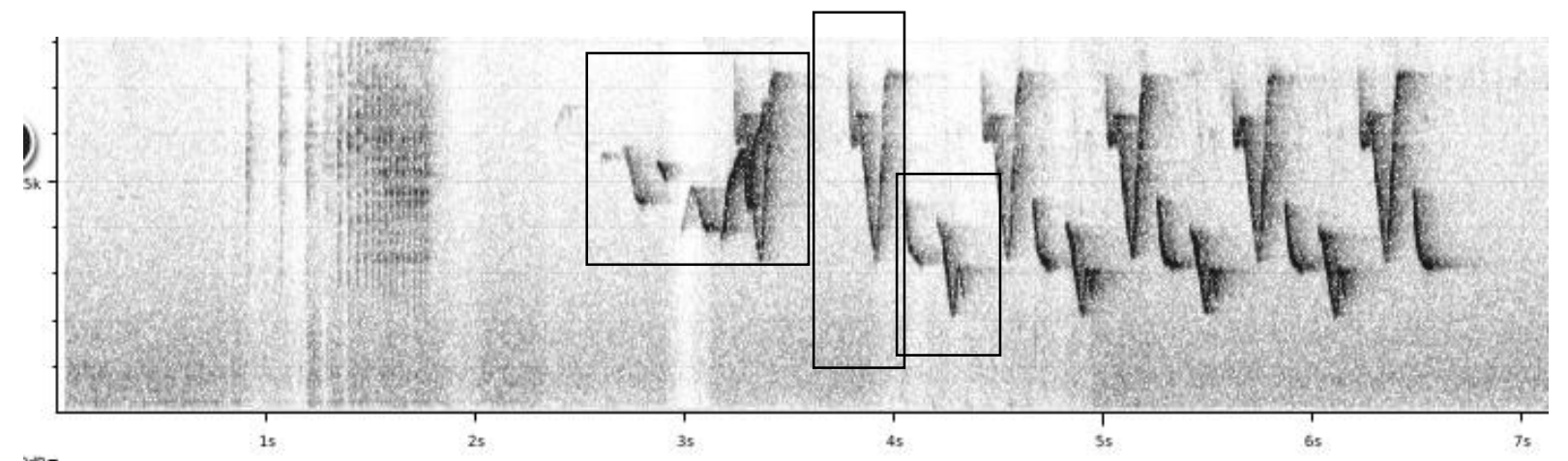

'I phrase of male'
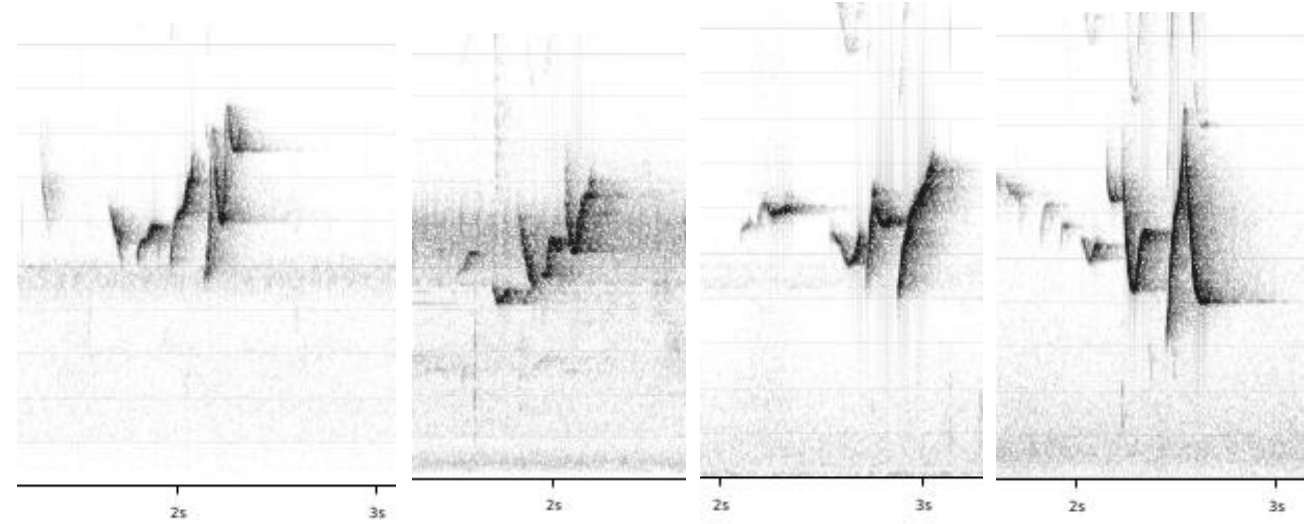

modestus

Duet

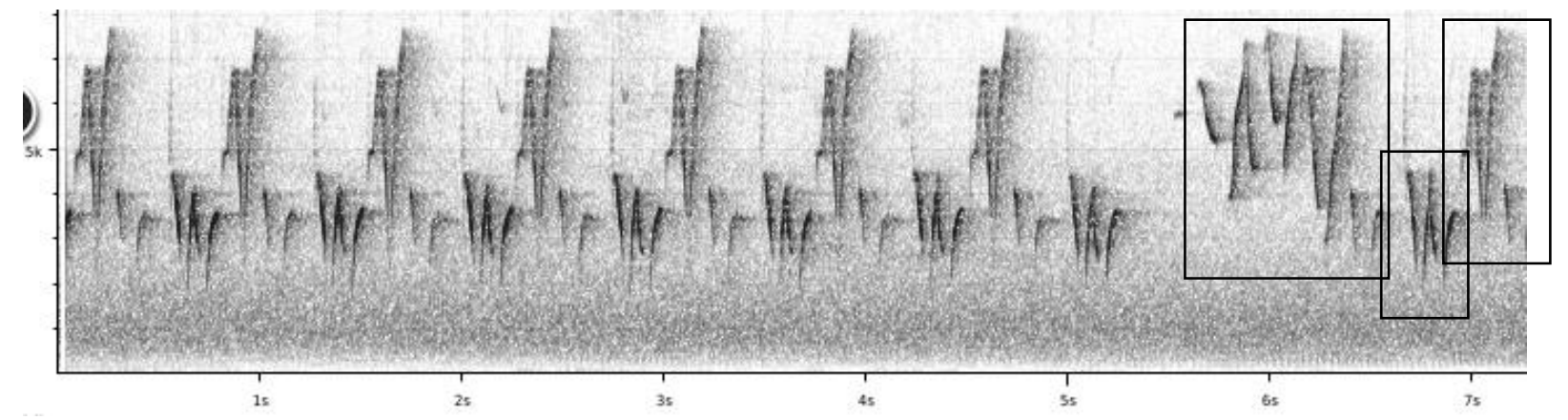

'I phrase of male'

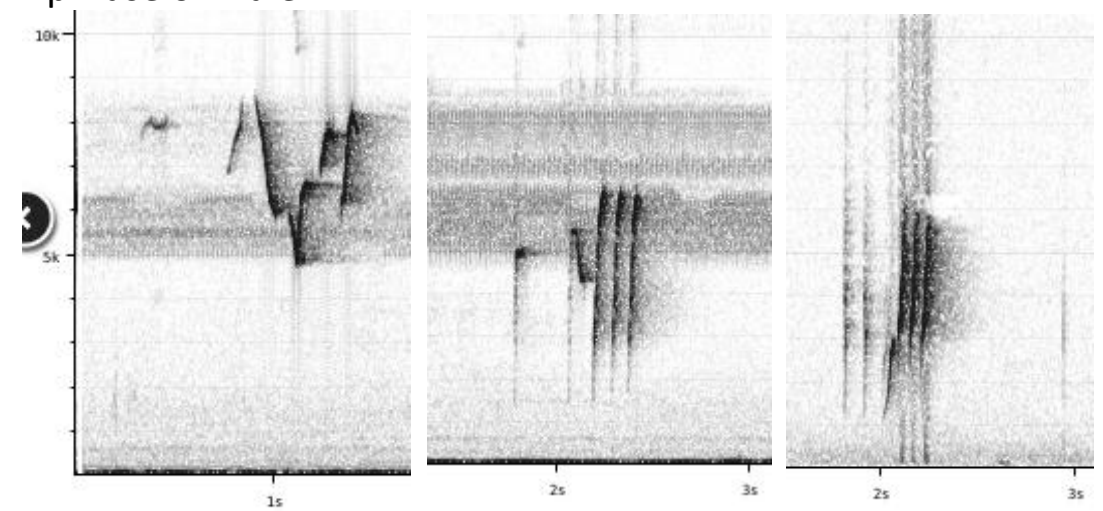



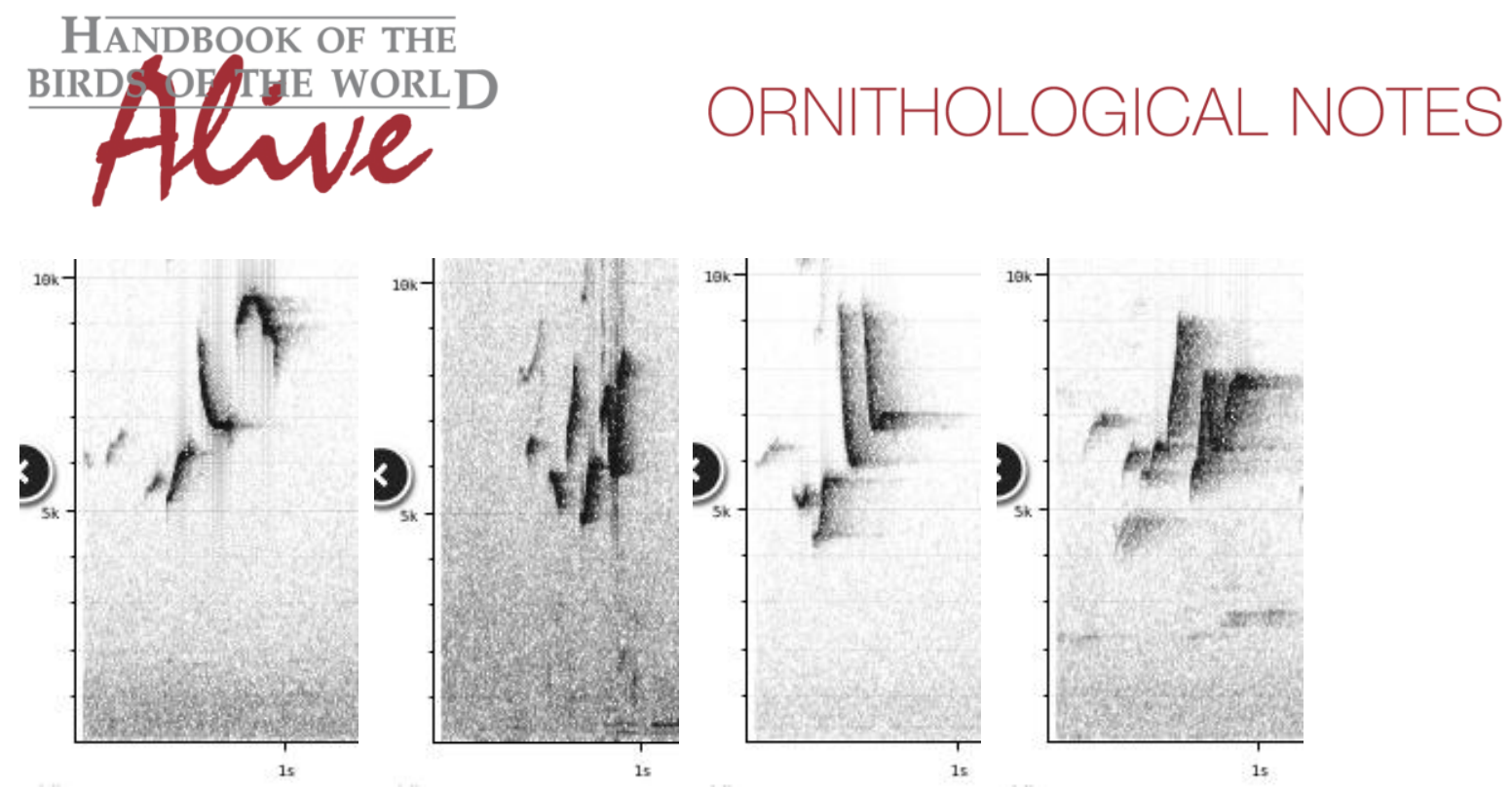

From the available recordings, no clear vocal differences are apparent.

The short song (I phrase) is highly variable in both races. Basic sound parameters such as phrase length, $\mathrm{min} / \mathrm{max}$ freq., \# of notes etc. have similar ranges.

Duet song with A and B phrases is also similar, basic parameters don't show clear differences. A large set of full duet recordings would be needed to find out if there are any consistent (subtle) differences.

These findings are somewhat surprising as NACC followed Saucier et al. (2015) in elevating both races to species rank citing as important supporting evidence significant differences in song duet pattern.

Saucier et al. (2015) apparently only used evidence from a previous study by Mann et al. (2003), indicating that there are substantial differences in duetting structure.

Mann et al. (2003) however only compared his own observations for modestus (??) and zeledoni with descriptions by Farabaugh (1983) of elutus. (Farabaugh (1983) is a PhD dissertation of which we were unable to find any details).

In Saucier et al. (2015) it is said that elutus 'differs in the crucial introductory phrases', without explaining what those differences may be (absence thereof or comparable differences?).

Mann et al. (2003) was the first to describe the 'I-A-B structure' of duetting in T.m. zeledoni, and in the same way Cuthbert et al. (2007) described the I-A-B structure for T.m.modestus. Mann et al. (2009) went a step further and proved that song structure is characteristic for every genus, with duet structure for the entire Cantorchilus genus I-A-B-A-B-A...: a male intro, followed by alternating female and male phrases.

By proving that the entire genus Cantorchilus has a song initiated by a male intro phrase, Mann basically says this is also the case for elutus (despite being aware of Farabaugh 1983). Mann et al. (2009) does not specifically mention race elutus, but Farabaugh's work is briefly discussed, suggesting it was not done very thoroughly (?) and not specifically dealing with elutus (!) (citation: Farabaugh, 1983, working in Panama, considered data from just a small subgroup of sympatric species (he compared six species, but detailed data were only collected on two of those), furthermore, the study had no access to well-resolved phylogeny for the genus...). 

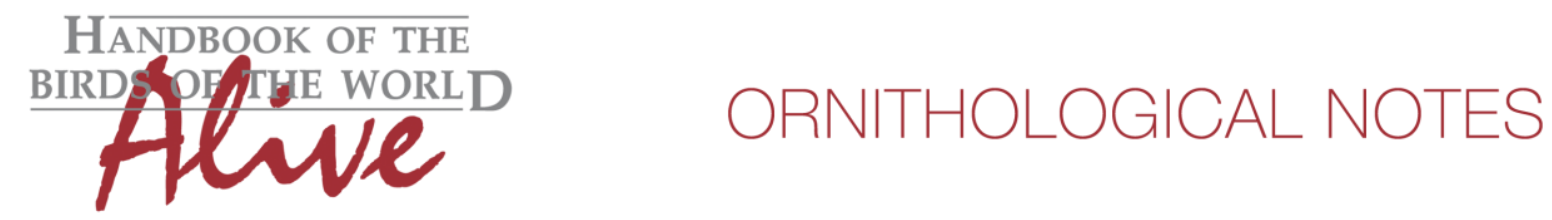

In this literature search, we have not found any concrete description of what differences in 'I phrase' there may be between elutus and modestus and it is unlikely that Farrabaugh, who only worked in Panama would have found detailed differences between the 'I phrase' of elutus and modestus. It seems much more likely (but to be proven by the Farabaugh PhD) he simply did not discover the use of such intro I-phrases in the duet identical to the 'short song', which prompted Mann (in 2003) to indicate this vocal difference with his own findings:

"This pattern differs from that described by Farabaugh (1983) for the closely related T. modestus elutus in Panama, in which the male produces vocalizations like the introductory phrases described here, but only when singing alone. However, preliminary analysis of our data on a third subspecies of Plain Wren, T. modestus modestus in Costa Rica, does indicate the presence of a song pattern like that of zeledoni (the subject of the present study). There is no doubt from our study that the I-phrase of the Plain Wren is an integral part of the duet, as it is rare for the female to produce her A-phrase without being stimulated to do so by the male."

But as already mentioned, Mann later (2009) in a wider comparison, concluded that duet structure was the same for the entire genus, all members of the genus using such 'I phrases'.

And finally, as already shown above, we have several examples of elutus which clearly show the IABABA.. structure:

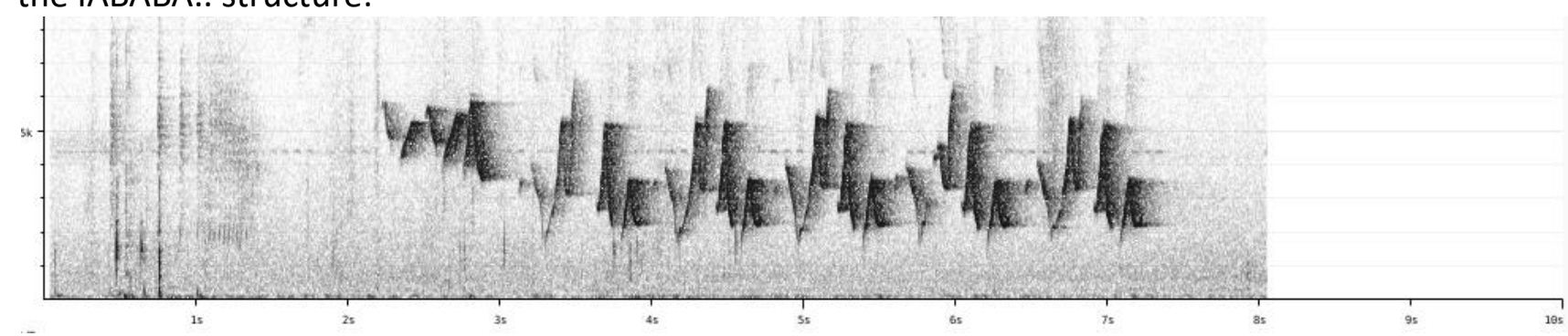

We can thus conclude that Farrabaugh's findings have been proven wrong and thus the statements about voice in Saucier et al. (2015) should be discarded !

\section{About Canebrake Wren T. zeledoni}

Stiles \& Skutch (1989) indicate: Songs and calls are generally lower-pitched and more throaty; also gives a series of harsh slurred whistles.

Some examples of full I-A-B duet song:

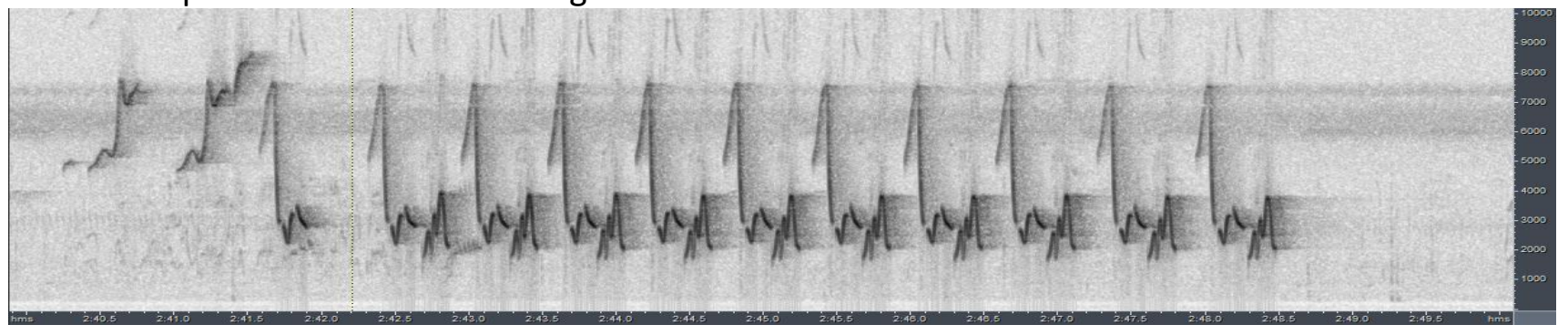




\section{HANDBOOK OF THE \\ Aluve}

\section{ORNITHOLOGICAL NOTES}

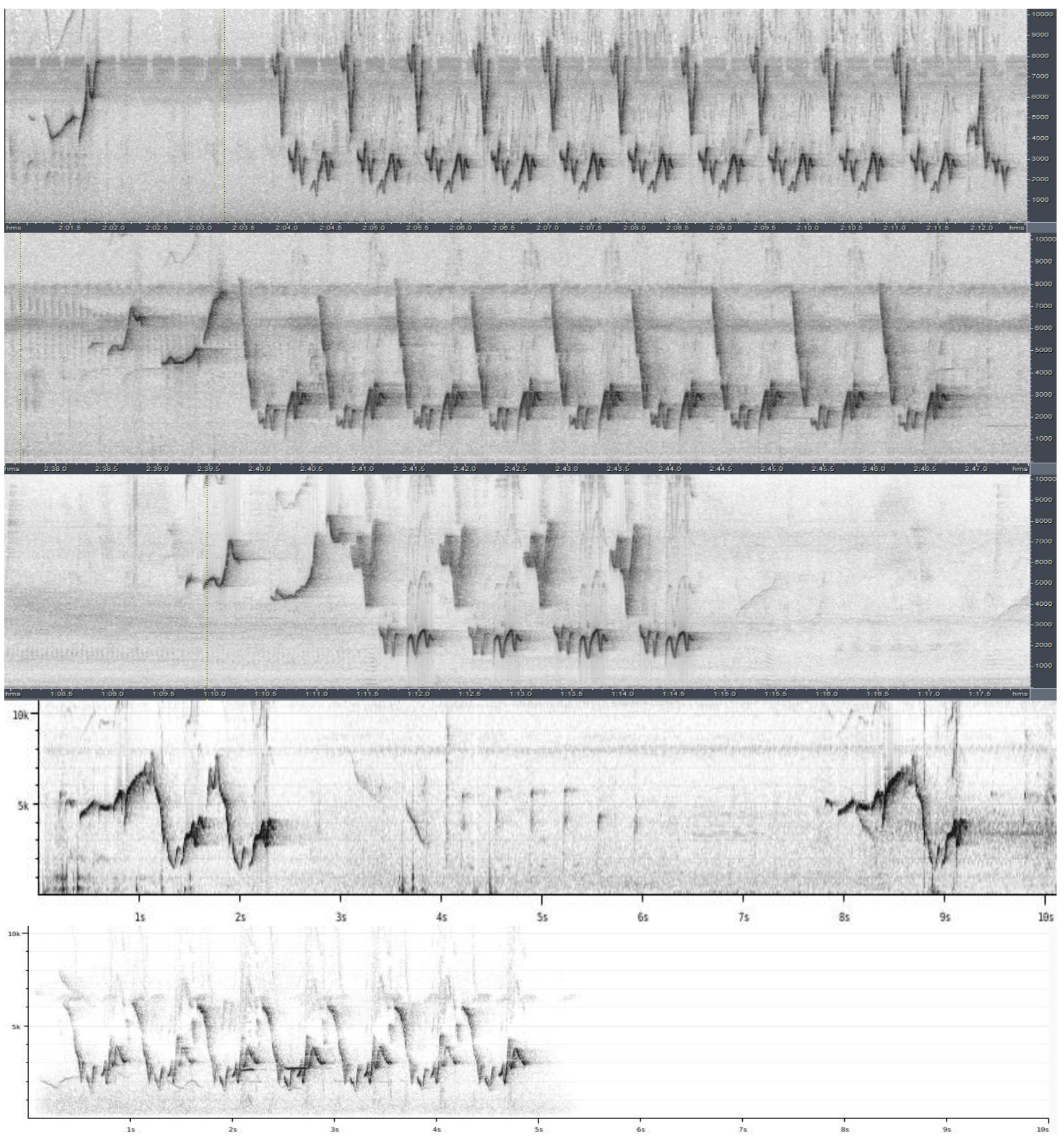

This seems to confirm indeed quite a different duet song:

Presumed female phrase $A$ covers a very large freq. range including a sharply down- or upslurred note, while the $B$ phrase of presumed male has a very narrow frequency range and is low-pitched $(<4 \mathrm{kHz})$. Note shapes are also clearly more curly, not dagger-shaped as in the above-treated two races.

More analysis would be needed, but this difference seems to be quite important and constant (score 3).

To uncover more subtle differences between the duet song of the 3 races we would need a larger set of complete IABAB duets. 

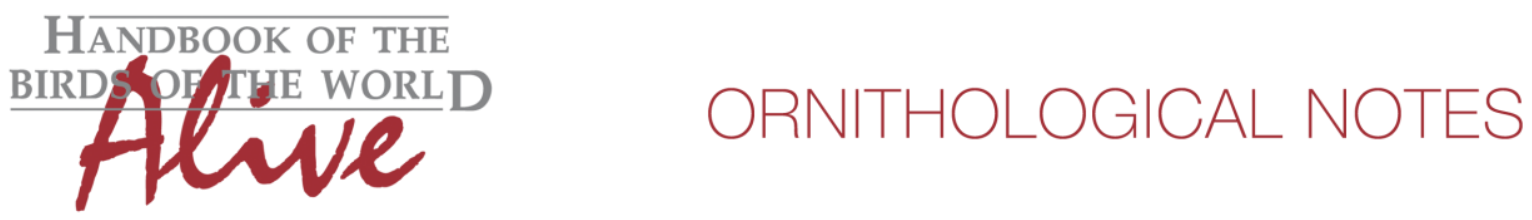

This note was finalized on 25th July 2016, using sound recordings available on-line at that moment. We would like to thank in particular the sound recordists who placed their recordings for this species on XC.

\section{References}

Cuthbert, J.L. \& Mennill, D.J. (2007). The duetting behaviour of Pacific Coast Plain Wrens. The Condor 109(3): 686-692.

Mann, N.I., Marshall-Ball, L. \& Slater, P.J.B (2003). The complex song duet of the Plain Wren. The Condor 105(4): 672-682.

Mann, N.I., Dingess, K.A., Barker, F.K., Graves, J.A. \& Slater, P.J.B. (2009). A comparative study of song form and duetting in Neotropical Thryothorus wrens. Behaviour 146(1): 1-43.

Saucier, J.R., Sánchez, C. \& Carling, M.D. (2015). Patterns of genetic and morphological divergence reveal a species complex in the Plain Wren (Cantorchilus modestus). Auk 132(4): 795-807.

Stiles, F.G. \& Skutch, A.F. (1989). A Guide to the Birds of Costa Rica. Christopher Helm. London.

Tobias, J.A., Seddon, N., Spottiswoode, C.N., Pilgrim, J.D., Fishpool, L.D.C. \& Collar, N.J. (2010). Quantitative criteria for species delimitation. Ibis 152(4): 724-746.

\section{Recommended citation}

Boesman, P. (2016). Notes on the vocalizations of Plain Wren (Thryothorus modestus) and Canebrake Wren (Thryothorus zeledoni). HBW Alive Ornithological Note 294. In: Handbook of the Birds of the World Alive. Lynx Edicions, Barcelona. (retrieved from http://www.hbw.com/node/1251742 on 13 October 2016). 